\title{
Genetic Engineering: A Promising Tool to Engender Physiological, Biochemical, and Molecular Stress Resilience in Green Microalgae
}

\author{
Freddy Guihéneuf ${ }^{11}$, Asif Khan ${ }^{2 t}$ and Lam-Son P. Tran ${ }^{3,4 *}$ \\ 'Botany and Plant Science, School of Natural Sciences, Ryan Institute, National University of Ireland Galway, Galway, \\ Ireland, ${ }^{2}$ Research Group Germline Biology, Centre for Organismal Studies (COS), Heidelberg University, Heidelberg, \\ Germany, ${ }^{3}$ Plant Abiotic Stress Research Group \& Faculty of Applied Sciences, Ton Duc Thang University, Ho Chi Minh City, \\ Vietnam, ${ }^{4}$ Signaling Pathway Research Unit, RIKEN Center for Sustainable Resource Science, Tsurumi, Japan
}

\section{OPEN ACCESS}

Edited by:

Mohammad Anwar Hossain, Bangladesh Agricultural University,

Bangladesh

Reviewed by:

Benoit Schoefs,

University of Maine, France

Boris Zorin,

Ben-Gurion University of the Negev,

Israel

*Correspondence:

Lam-Son P. Tran

sontran@tdt.edu.vn;

son.tran@riken.jp

tThese authors have contributed equally to this work.

Specialty section: This article was submitted to

Plant Biotechnology,

a section of the journal

Frontiers in Plant Science

Received: 08 February 2016 Accepted: 14 March 2016

Published: 31 March 2016

Citation:

Guihéneuf F, Khan A and Tran L-SP

(2016) Genetic Engineering:

A Promising Tool to Engender

Physiological, Biochemical, and Molecular Stress Resilience

in Green Microalgae.

Front. Plant Sci. 7:400

doi: 10.3389/fpls.2016.00400
As we march into the 21 st century, the prevailing scenario of depleting energy resources, global warming and ever increasing issues of human health and food security will quadruple. In this context, genetic and metabolic engineering of green microalgae complete the quest toward a continuum of environmentally clean fuel and food production. Evolutionarily related, but unlike land plants, microalgae need nominal land or water, and are best described as unicellular autotrophs using light energy to fix atmospheric carbon dioxide $\left(\mathrm{CO}_{2}\right)$ into algal biomass, mitigating fossil $\mathrm{CO}_{2}$ pollution in the process. Remarkably, a feature innate to most microalgae is synthesis and accumulation of lipids (60-65\% of dry weight), carbohydrates and secondary metabolites like pigments and vitamins, especially when grown under abiotic stress conditions. Particularly fruitful, such an application of abiotic stress factors such as nitrogen starvation, salinity, heat shock, etc., can be used in a biorefinery concept for production of multiple valuable products. The focus of this mini-review underlies metabolic reorientation practices and tolerance mechanisms as applied to green microalgae under specific stress stimuli for a sustainable pollution-free future. Moreover, we entail current progress on genetic engineering as a promising tool to grasp adaptive processes for improving strains with potential biotechnological interests.

Keywords: microalgae, abiotic stresses, genetic engineering, strain improvement, potential applications

\section{INTRODUCTION}

Due to their taxonomic and biochemical diversity, microalgae symbolize an unconventional source of molecules (Stengel et al., 2011). For example, the inherent nature of microalgae to accumulate lipids, carbohydrates, and secondary metabolites under abiotic stress can be applied in a biorefinery concept for generation of value-added compounds (Markou and Nerantzis, 2013). Nonetheless, transgenic microalgae impact diverse businesses such as energy, human and animal nutraceuticals, pharmaceuticals, health, beauty, and exquisite chemicals (Rasala et al., 2014). As naturalized for bacteria, yeasts, and plants, genetic engineering, therefore, constitutes promising strategy for studying abiotic stress responses in microalgae through novel phenotypes and specific traits. Conversely, microalgae as model photosynthetic organisms represent an ideal experimental 
system to study major plant processes, as mimicking algal strategies to sense, respond and cope with abiotic stress can radically improve growth and metabolite productivity in plants. Over the years, significant advances in genetic manipulation of green microalgae have been achieved (Mayfield and Golden, 2015), as exemplified through production of omega- 3 fatty acids, carotenoids, biofuels, as well as improved photosynthetic growth (Gimpel et al., 2015). Despite tremendous advances in sequenced genome, in particular for chlorophytes and heterokonts (i.e., diatoms), major obstacles feature need of additional wellestablished transformation vectors, potential inability to engineer and specifically localize transgenic proteins to sub-cellular locations and robust expression of multiple nuclear-encoded transgenes (Gong et al., 2011; Scranton et al., 2015). In this minireview, we discuss recent examples highlighting futuristic use of genetic engineering to design strains with potential biotechnological interests (Figure 1). Moreover, we surmise major abiotic stress resilience strategies envisaged in unicellular eukaryotic green microalgae.

\section{Current Progress on Genetic and Metabolic Engineering of Green Microalgae \\ What We Know and What Is Available?}

The pursuit of stress-tolerant strains has seen an unprecedented surge of algal transgenesis for recombinant proteins, enhanced photosynthesis, and key metabolite pathways, as well as production of precious nutraceuticals, pharmaceuticals, and biofuels (Gangl et al., 2015). Coupled to this, advanced cultivation of novel species with genome-wide omics (genomics, transcriptomics, lipidomics, and metabolomics) has facilitated successful transformation of microalgae (e.g., Chlamydomonas reinhardtii, Phaeodactylum tricornutum, Thalassiosira pseudonana, Porphyridium sp., Nannochloropsis gaditana, Ostreococcus tauri, Haematococcus pluvialis, etc.). Previously, lack of genome and transcriptome data, as well as efficient tools for algal transformation prevented their genetic manipulation. Consequently, algal transformation systems had to be revisited, developed anew, including methods to introduce transgenic DNA, identification of suitable promoters, distinct selectable markers and expression vectors, as well as needs for codon usage optimization (Qin et al., 2012; Hlavova et al., 2015).

Despite gigantic successes being achieved, only a few algal species still show firm and stable expression of foreign proteins. Increasing evidence suggests intrinsic algal gene silencing mechanisms; albeit repressive histone $\mathrm{H} 3$ lysine methylation, DNA cytosine methylation, RNA interference and microRNA-mediated gene regulation for instable foreign transcript or protein degradation (Kim et al., 2015). Likewise, the knowledge of such transgene evading mechanisms will be useful in regulating efficient protein production in metabolically engineered microalgae. Additionally, the emergence of fast and reliable next-generation sequencing techniques have sped up genome sequencing programs and transcriptomic research (Morozova and Marra, 2008). As a result, it is now possible to directly correlate the ensuing transcriptomic, proteomic, and metabolomic profile with respect to pre-determined environmental stimuli, bridging the gap between microalgal genotype and observed phenotype (Dong and Chen, 2013).

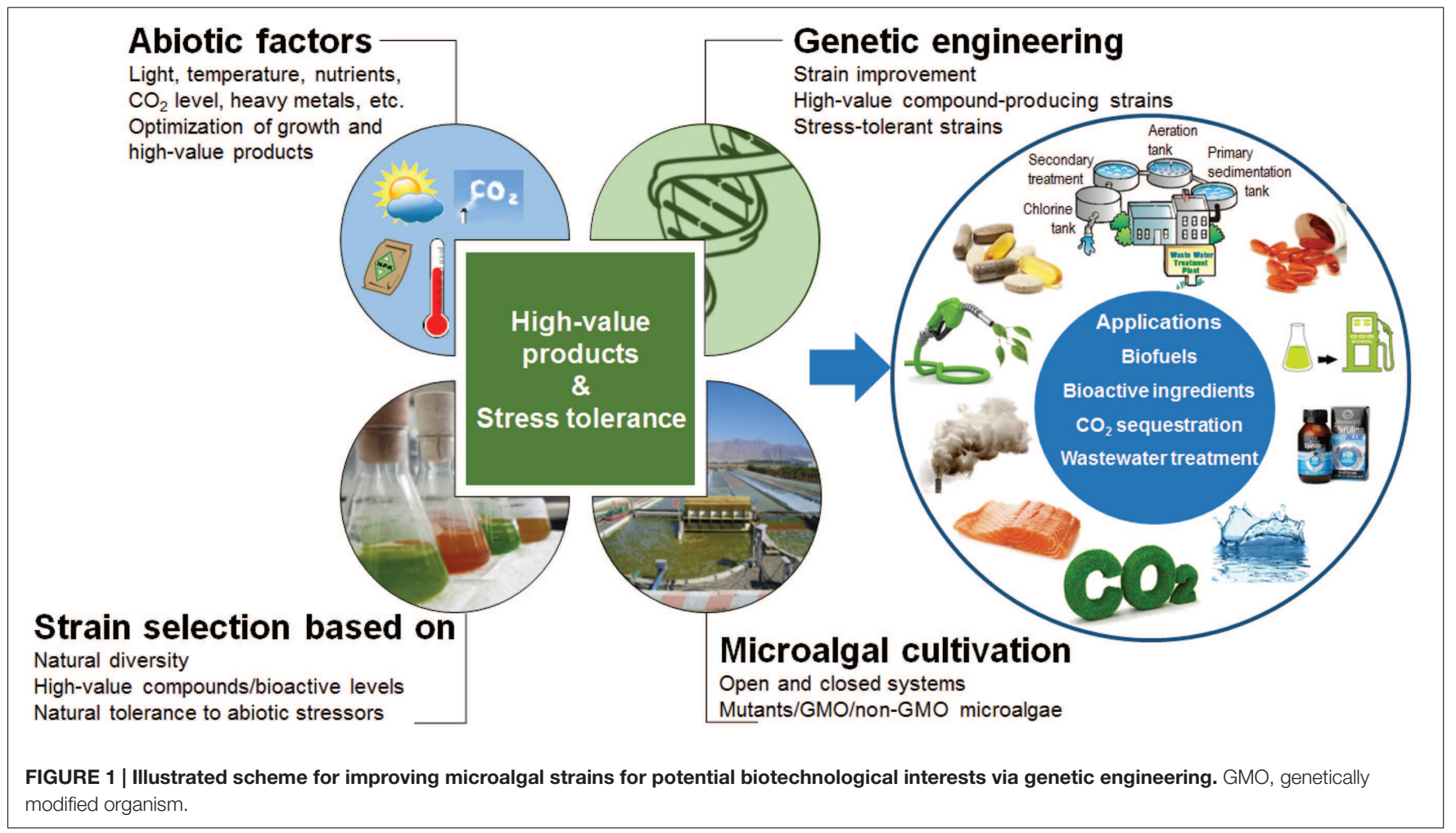


In future, a combination of transcriptomic, proteomic, and metabolomic studies will be crucial in demarcating gateways to metabolic flux for boosting algal strain-engineering strategies (Jones and Mayfield, 2012). In addition, a battery of bioinformatic softwares like Algal Functional Annotation Tool, GreenCut2, AlgaGEM, Bag2D, PredAlgo (de Oliveira Dal'Molin et al., 2011; Karpowicz et al., 2011; Lopez et al., 2011; Tardif et al., 2012; Yao et al., 2015), and in silico kinetic and metabolic reconstruction models ${ }^{1}$ are now available for gene/protein characterization, gene metabolic alterations, and predicting proteins subcellular localizations at a whole genome level in various algal species. For example, an in silico metabolic reconstruction map allowed characterization of light-induced metabolic response for $>1000$ genes in Chlamydomonas (Chang et al., 2011). Likewise, the Chlamydomonas resource center ${ }^{2}$ harbors a collection of $\sim 300$ plasmids and $>2700$ strains for sustaining research within diverse aspects of algal cell biology. Additionally, a genomewide Chlamydomonas insertional mutant library ${ }^{3}$ containing $>20,000$ mutants covering 10,301 genes (58\% of the genome) and cataloged at Chlamydomonas resource center has been recently reported (Li et al., 2016).

\section{Genetic Engineering: Progress and Future Prospects}

With an eye toward the future, methods to engineer entire biochemical pathways or multigene traits via homologous/heterologous recombination and development of optimized cloning vectors are underway, as demonstrated by stable integration and subcellular localization of reporter proteins in the chloroplast and nuclear genomes of C. reinhardtii (NoorMohammadi et al., 2012; Rasala et al., 2014; Scranton et al., 2016). Such a strategy can be advantageous for foreign gene integration, omitting positional side effects and transcriptional/posttranscriptional gene silencing processes associated with nuclear expression (Kim et al., 2015). In addition, successful yet simple nuclear gene targeting systems have been described in Chlamydomonas (Zorin et al., 2009). Novel permutations of promoter and $5^{\prime} \mathrm{UTR}$, like $16 \mathrm{~S}$ rRNA promoter and atpA 5'UTR have also been illustrated for sufficient heterologous transgene expression (Rasala et al., 2011) and robust expression of transgenic proteins within the $C$. reinhardtii chloroplast (Tissot-Lecuelle et al., 2014). Examples of metabolic engineering in microalgae comprise codon optimized expression of genes hemH and $l b a$ in the chloroplast of $C$. reinhardtii for optimum bio-hydrogen generation (Wu et al., 2011). Recently, synthetic promotors were generated to drive robust nuclear gene expression in Chlamydomonas (Scranton et al., 2016).

In search of optimal methods for exogenous DNA delivery within rigid algal cell walls, a zinc oxide nanowire array microdevice system was recently elaborated for $C$. reinhardtii (Bae et al., 2015) with recorded efficiency $6.52 \times 10^{4}$ - and $9.66 \times 10^{4}$-fold higher than traditional glass bead beating and electroporation methods. Besides, a biocontainment method for transplastomic microalgae was reported via codon reassignment

\footnotetext{
${ }^{1}$ www.ebi.ac.uk/biomodels-main

${ }^{2}$ http://www.chlamycollection.org/

${ }^{3}$ https://www.chlamylibrary.org/
}

in the chloroplast of C. reinhardtii (Young and Purton, 2015). Such a codon reassignment strategy can be potentially useful for solving imminent problems in chloroplast engineering of genes whose products are toxic to Escherichia coli cells. Similarly, a self-cloning-based (cloning DNA from a donor into a recipient, between which the natural exchange of DNA is possible) positive selection system for breeding and genetic transformation of Pseudochoricystis ellipsoidea was developed (Kasai et al., 2015). Such recombinant microalgae are considered natural (nonGMO) in Japan and are not governed under the Cartagena domestic law with regards to GMO biosafety (Lusser et al., 2012; USDA Japan Reports, 2014). Such algal molecular breeding techniques may form basis for future large-scale cultivation in outdoor open pond cultivation (Ho et al., 2014).

Finally, reports for high level targeted genome editing in C. reinhardtii via zinc finger nucleases (Sizova et al., 2013), transcription activator-like effectors (TALE; Gao et al., 2014), and lately clustered regularly interspersed short palindromic repeat (CRISPR) system are emerging (Jiang et al., 2014). CRISPR-associated protein 9 (CAS9) is an RNA-guided DNA nuclease successfully practiced for targeted mutations into eukaryotic genomes (Dominguez et al., 2016). Although stable transformants of $C$. reinhardtii expressing the CAS9 protein could not be recovered, in future, such studies would serve as gold standard for dedicated nuclear, chloroplast, and mitochondria genome-editing strategies.

\section{Microalgal Stress Response Strategies Abiotic Stress Tolerance in Green Microalgae}

Owing to incredible metabolic plasticity of microalgae (Stengel et al., 2011), numerous studies have outlined ramifications of abiotic stress influencing algal biology and metabolism. High light, temperature, salinity, metals, $\mathrm{CO}_{2}$ levels, and nutrient depletion affect growth, photosynthesis, and biochemical composition in a species-specific manner (Perales-Vela et al., 2006; Solovchenko and Khozin-Goldberg, 2013).

One of the most detrimental abiotic stressor damaging algae is high light intensity, when absorption of light energy surpasses the capacity for light utilization in photosynthesis. Several mechanisms termed as non-photochemical quenching (NPQ) exist, to avoid this photodamage (Allorent et al., 2013; Mayank et al., 2015). NPQ consists of three components: qE (energydependent quenching), qI (photoinhibitory quenching), and qT (light-state transition; Eberhard et al., 2008; Depauw et al., 2012). The $\mathrm{qE}$ increases the thermal dissipation of excessive light energy and represents the major photo-protective process characterizing vascular plants, green microalgae and diatoms (Müller et al., 2001; Roháček et al., 2014). In model green alga C. reinhardtii, NPQ is stimulated by variations in $\mathrm{pH}$ in the thylakoid lumen, in response to high light intensity, triggering the xanthophyll cycle (XC) and activating the PSII LHC stress-related (LhcSR) proteins (Finazzi et al., 2006; Maruyama et al., 2014; Wobbe et al., 2016). The latter initiates an onset of NPQ by perceiving lumenal $\mathrm{pH}$ environment and in a concentration-dependent manner aggravates fluorescence quenching; the XC plays key role in boosting light harvesting and photoprotection (Goss and 
Jakob, 2010). Nevertheless, studies of their NPQ and XC activities have suggested species-specific differences in process of excessive energy dissipation between six green microalgae (Quaas et al., 2015). Of interest, microalgal species like Dunalliela spp. and $H$. pluvialis display the capacity to synthetize and accumulate tremendous amounts of secondary carotenoids $(\beta$-carotene and astaxanthin, respectively) under stress (Lamers et al., 2012; Scibilia et al., 2015). In photosynthetic organisms, response to high light involves enormous changes in expression of lightregulated genes and their regulatory components (Lemoine and Schoefs, 2010). Over the years, dedicated gene expression studies with microalgae exposed to different light regimes were undertaken, unveiling peculiar molecular actors associated with light stress responses (e.g., Lhcx gene group in diatoms, known to be closely related to $L h c S R$ genes of C. reinhardtii; Maruyama et al., 2014).

Microalgae further picture a suite of adaptive mechanisms in response to changes in salinity, i.e., passive "osmometer" behavior. Such a profile largely depends on physical and chemical characteristics of the cell wall membrane, regulation of water fluxes, mechanisms to equilibrate intracellular ionic levels using ion-selective channels and carriers, and synthesis or degradation of low-molecular-weight organic solutes (Kirst, 1990). The halotolerant green alga, Dunaliella salina, has been described as a model alga for deducing response of plant cells to salt stress (Cowan et al., 1992). Employing a proteomic approach for salinity stress induced proteins in Dunaliella, Liska et al. (2004) decoded up-regulation of major Calvin cycle enzymes, starch mobilization enzymes and enzymes involved in redox energy generation; factors involved in protein production and degradation; and an analog of bacterial $\mathrm{Na}^{++}$-redox transporters. The results are suggestive of Dunaliella's response to high salinity by enhancing photosynthetic $\mathrm{CO}_{2}$ consumption and allocating carbon and energy budget for synthesis of glycerol, its osmoprotective component. On the same lines, salt-stress up-regulated the carotenoid ketolase $(B K T)$ in Chlorella zogingiensis and enhanced the accumulation of canthaxanthin and astaxanthin. High salinity also stimulated the generation of reactive oxygen species, which in turn triggered the up-regulation of distinct carotenogenic genes and increased build-up of antioxidant carotenoids (Li et al., 2009).

Changes in temperature are known to strongly affect growth, photosynthetic activity and biochemical composition in microalgae (Geider, 1987; Renaud et al., 2002; Claquin et al., 2008). Indeed, higher temperatures often result in decline in protein production and rise in lipid and carbohydrates levels. An increase in polyunsaturated fatty acids (PUFAs) might be one of the ways microalgae adjust to low-temperature and preserve membrane fluidity (Jiang and Gao, 2004). Interestingly, few microalgae exhibit high temperature tolerance up to 40-42 ${ }^{\circ} \mathrm{C}$ (Hanagata et al., 1992; Sakai et al., 1995; de-Bashan et al., 2008). Heat shock proteins (HSPs) are molecular chaperones, crucial during heat shock response and ensuing adaptive homeostases against environmental stresses. 17 small HSPs has been identified from complete genome sequences of five diverse algae: C. reinhardtii, Cyanidioschyzon merolae, Ostreococcus lucimarinus, O. tauri, and T. pseudonana (Waters and Rioflorido,
2007). However, sequence analysis reveals that the diversity and abundance of algal small HSPs does not fully correlate with acclimation to extreme temperatures. Recently, two small HSPs have been shown to be up-regulated and activated at a threshold temperature of $\sim 36^{\circ} \mathrm{C}$ in C. reinhardtii (Kobayashi et al., 2014). These results stress the advantage of an exclusive temperature-sensing system in the evolution and resilience to elevated temperatures among microalgae.

\section{Mechanisms of $\mathrm{CO}_{2}$ Concentration and Heavy Metal Tolerance}

Rise in atmospheric $\mathrm{O}_{2}$ and decrease in oceanic, dissolved inorganic carbon during eco-genesis enabled photoautotrophic organisms to formulate sophisticated $\mathrm{CO}_{2}$-concentrating mechanisms (CCMs). Such mechanisms enhance $\mathrm{CO}_{2}$ uptake by increasing $\mathrm{CO}_{2}$ concentration around ribulose-1,5-bisphosphate carboxylase/oxygenase (Rubisco), an enzyme of the chloroplast stroma that catalyzes the entry of $\mathrm{CO}_{2}$ into the Calvin-BensonBassham cycle to maintain sufficient photosynthesis (Raven, 2010). To date, numerous published reports have described low- $\mathrm{CO}_{2}$-acclimation/adaptation within some cyanobacteria and unicellular eukaryotes; but, information regarding high$\mathrm{CO}_{2}$ tolerance processes remains elusive. One $\mathrm{CO}_{2}$ mitigation strategy consists of selecting and developing strains that stand rigorously high $\mathrm{CO}_{2}$ levels to couple microalgal-mediated $\mathrm{CO}_{2}$ fixation and production of biofuels and other secondary metabolites (Bhola et al., 2014). Since $\mathrm{CO}_{2}$ tolerance varies greatly between species, microalgae have been arbitrarily divided into $\mathrm{CO}_{2}$-sensitive (inhibited by $<2-5 \% \mathrm{CO}_{2}$ ) and $\mathrm{CO}_{2}$-tolerant (surviving up to $20 \% \mathrm{CO}_{2}$ ) groups (Miyachi et al., 2003). An example of such $\mathrm{CO}_{2}$-tolerant species includes chlorophytes Chlorella sp. KR-1 and Chlorococcum littorale that demonstrate rapid growth at 40 and $60 \% \mathrm{CO}_{2}$, respectively (Iwasaki et al., 1996; Sung et al., 1999). Principal factors responsible for high $\mathrm{CO}_{2}$ tolerance in such extremophile symbiotic species constitute state transitions in photosynthetic apparatus that augment ATP generation, enhanced activity of $\mathrm{H}^{+}$-ATPase for pumping protons out of the cell, hasty shutdown of CCMs, adjustment of fatty acid composition and diversion of excess photosynthates to generation of energy-rich compounds, such as triacylglycerols (Solovchenko and Khozin-Goldberg, 2013).

Microalgae also possess molecular machinery that allows them to distinguish between non-essential and essential heavy metals (Perales-Vela et al., 2006). This ability makes microalgae better suited for treatment of heavy metal polluted water, employing algal-based biotechnologies for waste-water remediation (Suresh Kumar et al., 2015). Indeed, microalgae take up and store toxic metals from the environment (Perales-Vela et al., 2006). For instance, microalgae can preferentially synthesize peptides capable to bind heavy metals. These peptides, as part of organometallic complexes, are additionally partitioned inside vacuoles to aid pertinent control of the cytoplasmic concentration of metal ions, thus nullifying their potential toxic effect (Cobbett and Goldsbrough, 2002). C. reinhardtii has been described as a model photosynthetic eukaryotic for investigating heavy metal tolerance or homeostasis due 
to molecular and genetic tools available for this species (Hanikenne, 2003). For example, phytochelatins (PC), lowmolecular weight peptides, containing sulfur rich cysteine amino acid have been elicited as major intracellular cadmium (Cd) chelators in C. reinhardtii ( $\mathrm{Hu}$ et al., 2001). In Dunaliella tertiolecta, PC, inducibly synthesized by zinc treatment, can function both in detoxifying heavy metals and alleviation of oxidative stress (Tsuji et al., 2002). Thioredoxins (TRXs) are also known to accord heavy metal detoxification in Chlamydomonas as exemplified by two TRX genes being differentially stimulated by $\mathrm{Cd}$ and mercury (Lemaire et al., 1999). As glutathione (GSH)-heavy metal adducts serve as substrates for PC synthase, an earlier study centered on two strains of Scenedesmus acutus (wild type and $\mathrm{Cr}^{6+}$ tolerant) reported the constitutive cysteine concentration higher in the $\mathrm{Cr}^{6+}$-tolerant strain (Torricelli et al., 2004). When the cells were subjected to $\mathrm{Cd}^{2+}$, the tolerant strain had increased levels of reduced GSH and class III metallothioneins (MtIII) as compared to the wild-type strain. Finally, proline (Pro) has also been reported to play a dominant role in alleviating environmental stress including heavy metal stress in plants, microorganisms and microalgae (Siripornadulsil et al., 2002).

Clearly, abiotic stress has the ability to reorient a holistic and sometimes specific microalgal metabolism as an efficient means for increasing the production of selected compounds. Keeping this in mind we highlight in the next section recent advances in microalgal engineering which, when combined with sophisticated physiological and biophysical approaches, may enhance microalgal stress resilience under disparate conditions.

\section{Examples of Stress-Resilience in Microalgae via Genetic Engineering}

Despite most engineering strategies favoring increased production of high value compounds (e.g., antioxidant pigments and PUFAs) and biofuel-molecules (e.g., hydrogen and triacylgycerol), recent works have been driven to develop resilient strains with applications like $\mathrm{CO}_{2}$ sequestration and heavy metal biomitigation (Table 1). For example, a moth bean $\delta 1$-pyrroline-5-carboxylate synthetase (P5CS) gene has been expressed in C. reinhardtii, with transformants displaying $80 \%$ higher free-Pro levels, rapid growth at toxic Cd concentrations,

TABLE 1 | Examples of green algal species aptly transformed to date together with methods applied and trait(s) enhanced for proficient metabolic or genetic engineering.

\begin{tabular}{|c|c|c|c|c|c|}
\hline Algal species & Transfection method & Modification & Genes & Trait(s) engineered & Reference \\
\hline \multirow[t]{6}{*}{$\begin{array}{l}\text { Chlamydomonas } \\
\text { reinhardtii }\end{array}$} & Glass beads & RNAi three target genes & $D G A T$ & $\begin{array}{l}24 \text { and } 37 \% \text { reduction in } \\
\text { TAGs with two genes } \\
34 \% \text { increase in TAGs with } \\
\text { one gene }\end{array}$ & Deng et al., 2012 \\
\hline & Glass beads & Nuclear overexpresion & $P S Y$ & 2.6-fold increase in lutein & Couso et al., 2011 \\
\hline & - & Insertional mutagenesis & CHT7 & $\begin{array}{l}\text { Repressor of cellular } \\
\text { quiescence under } \\
\text { nitrogen-replete conditions }\end{array}$ & Tsai et al., 2014 \\
\hline & Biolistics & Chloroplast expression & hemH \& Iba & $\begin{array}{l}\text { Increase in hydrogen } \\
\text { production }\end{array}$ & Wu et al., 2011 \\
\hline & Electroporation & Nuclear expression & P5CS (moth bean) & $\begin{array}{l}80 \% \text { higher free-Pro levels, } \\
\text { rapid growth under Cd } \\
\text { toxicity, four-fold more } \\
\text { binding to } \mathrm{Cd}\end{array}$ & $\begin{array}{l}\text { Siripornadulsil et al., } \\
2002\end{array}$ \\
\hline & Glass beads & $\begin{array}{l}\text { RNAi } \\
\text { LHC gene family }\end{array}$ & $\begin{array}{l}20 \text { genes encoding } \\
\text { LHCl, LHCll, CP26 and } \\
\text { CP29 down-regulated }\end{array}$ & $\begin{array}{l}\text { Antenna-size reduction } \\
\text { Increased competence for } \\
\text { cell cultivation under high } \\
\text { light intensity }\end{array}$ & Mussgnug et al., 2007 \\
\hline Chlorella ellipsoidea & Electroporation & Nuclear overexpression & $\begin{array}{l}\text { Lipogenesis } \\
\text { Transcription factors }\end{array}$ & $52 \%$ increase in total lipids & Zhang et al., 2014 \\
\hline Chorella minutissima & Electroporation & Nuclear overexpression & $\begin{array}{l}\text { Five genes encoding } \\
\text { TAG enzymes }\end{array}$ & $\begin{array}{l}\text { Twofold increase in TAGs } \\
\text { with all five genes } \\
\text { No change with individual } \\
\text { gene }\end{array}$ & Hsieh et al., 2012 \\
\hline Dunaliella salina & Electroporation & RNAi & PDS & $72 \%$ reduction of mRNA & Sun et al., 2008 \\
\hline $\begin{array}{l}\text { Haematococcus } \\
\text { pluvialis }\end{array}$ & Biolistics & Nuclear overexpression & PDS & $\begin{array}{l}26 \% \text { increase in } \\
\text { astaxanthin }\end{array}$ & $\begin{array}{l}\text { Steinbrenner and } \\
\text { Sandmann, } 2006\end{array}$ \\
\hline $\begin{array}{l}\text { Nannochloropsis } \\
\text { oceanica }\end{array}$ & Electroporation & Nuclear overexpression & $\Delta 12$-des & $\begin{array}{l}\text { Nitrogen-starvation induced } \\
\text { increase deposition of } \\
\text { polyunsaturated fatty acids } \\
\text { (PUFAs) in TAG }\end{array}$ & Kaye et al., 2015 \\
\hline
\end{tabular}

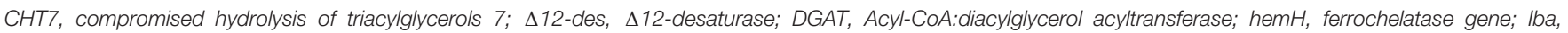

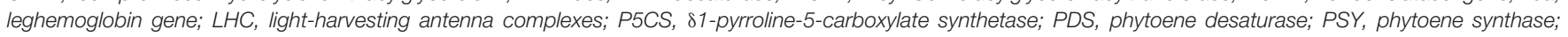
TAG, triacylglycerol. 
and tremendous binding at four-fold higher $\mathrm{Cd}$ concentration compared to wild-type cells (Siripornadulsil et al., 2002). The results propose role of free-Pro as an antioxidant in Cd-stressed cells with resulting higher GSH levels facilitating enhanced phytochelatin synthesis and sequestration of Cd. Expeditious transgenesis has been reported using such microalgae to enhance heavy metal sensitivity and binding specificity for contaminated wastewaters and sediments (Rajamani et al., 2007). Much interest has also been diverted toward engineering small and large subunits of Rubisco ( $r b c S$ and $\mathrm{rbcL}$ ) as targets for increasing net $\mathrm{CO}_{2}$ fixation (photosynthesis) and promoting $\mathrm{CO}_{2}$ sequestration through improvement of growth (Genkov et al., 2010; Whitney et al., 2011). In this regard, Chlamydomonas is a notable host for genetic manipulation, as changes can be made to both $r b c S$ and $r b c L$ genes. For instance, hybrid Rubiscos have been reported, by combining plant (Arabidopsis, spinach and sunflower) small ( $\mathrm{rbcS}$ ) subunits with algal large (rbcL) subunits via transformation of a $C$. reinhardtii mutant deficient in $r b c S$ gene (Genkov et al., 2010). Although the hybrid enzymes show $3-11 \%$ increase in $\mathrm{CO}_{2} / \mathrm{O}_{2}$ affinity, they retain optimal $\mathrm{V}_{\max }$ values and catalytically proficient Rubisco. The hybrid strains, however, lack chloroplast pyrenoids and display reduced photosynthesis. As asserted by Whitney et al. (2011), future research to engineer and test superior Rubiscos will considerably rely on algal model systems, particularly Chlamydomonas.

\section{REFERENCES}

Allorent, G., Tokutsu, R., Roach, T., Peers, G., Cardol, P., Girard-Bascou, J., et al. (2013). A dual strategy to cope with high light in Chlamydomonas reinhardtii. Plant Cell 25, 545-557. doi: 10.1105/tpc.112.108274

Bae, S., Park, S., Kim, J., Choi, J. S., Kim, K. H., Kwon, D., et al. (2015). Exogenous gene integration for microalgal cell transformation using a nanowire-incorporated microdevice. ACS Appl. Materials Interf. 7, 2755427561. doi: 10.1021/acsami.5b09964

Bhola, V., Swalaha, F., Ranjith Kumar, R., Singh, M., and Bux, F. (2014). Overview of the potential of microalgae for $\mathrm{CO}_{2}$ sequestration. Int. J. Environ. Sci. Technol. 11, 2103-2118. doi: 10.1007/s13762-013-0487-6

Chang, R. L., Ghamsari, L., Manichaikul, A., Hom, E. F. Y., Balaji, S., $\mathrm{Fu}, \mathrm{W}$., et al. (2011). Metabolic network reconstruction of Chlamydomonas offers insight into light-driven algal metabolism. Mol. Syst. Biol. 7:518. doi: 10.1038/msb.2011.52

Claquin, P., Probert, I., Lefebvre, S., and Veron, B. (2008). Effects of temperature on photosynthetic parameters and TEP production in eight species of marine microalgae. Aquatic Microbial Ecology 51, 1-11. doi: 10.3354/ame01187

Cobbett, C., and Goldsbrough, P. (2002). Phytochelatins and metallothioneins: roles in heavy metal detoxification and homeostasis. Annu. Rev. Plant Biol. 53, 159-182. doi: 10.1146/annurev.arplant.53.100301.135154

Couso, I., Vila, M., Rodriguez, H., Vargas, M. A., and León, R. (2011). Overexpression of an exogenous phytoene synthase gene in the unicellular alga Chlamydomonas reinhardtii leads to an increase in the content of carotenoids. Biotechnol. Prog. 27, 54-60. doi: 10.1002/btpr.527

Cowan, A. K., Rose, P. D., and Horne, L. G. (1992). Dunaliella salina: a model system for studying the response of plant cells to stress. J. Exp. Bot. 43, 1535-1547. doi: 10.1093/jxb/43.12.1535

de-Bashan, L. E., Trejo, A., Huss, V. A. R., Hernandez, J.-P., and Bashan, Y. (2008). Chlorella sorokiniana UTEX 2805, a heat and intense, sunlight-tolerant microalga with potential for removing ammonium from wastewater. Bioresour. Technol. 99, 4980-4989. doi: 10.1016/j.biortech.2007.09.065

de Oliveira Dal'Molin, C. G., Quek, L.-E., Palfreyman, R. W., and Nielsen, L. K. (2011). AlgaGEM - a genome-scale metabolic reconstruction of algae

\section{CONCLUSION}

Genetic manipulation of microalgae can provide feasible respite by meeting the immediate and long-term demands for food and fuel production on a sustainable basis. A clear step toward the realization of this goal is the development of microalgae-microbial fuel cells (mMFCs) that channelize the solar energy to electrical energy via algal metabolic pathways (Lee et al., 2015). Besides, genetic engineering of microalgae would supplement land plants and industrial biotechnology for value-added products, thereby saving land and air pollution. Already much is achieved through reinforced tools, including rapid sequencing of algal genomes, control of environmental stress conditions, as well as mining of new genes for enhancing lipid and bioactive productions, reducing photo-inhibition, and manipulation of Rubisco- and Calvin-cycle enzymes for metabolic engineering. The field of algal genetic engineering will require renewed attention both at basic and applied levels to envision a prosperous future.

\section{AUTHOR CONTRIBUTIONS}

FG and AK designed and conceptualized the idea and thereafter wrote different section or subsections in consultation with L-ST. All the authors read and finalized the version before submission.

based on the Chlamydomonas reinhardtii genome. BMC Genomics 12:S5. doi: 10.1186/1471-2164-12-s4-s5

Deng, X.-D., Gu, B., Li, Y.-J., Hu, X.-W., Guo, J.-C., and Fei, X.-W. (2012). The roles of acyl-CoA: Diacylglycerol acyltransferase 2 genes in the biosynthesis of triacylglycerols by the green algae Chlamydomonas reinhardtii. Mol. Plant 5, 945-947. doi: 10.1093/mp/sss040

Depauw, F. A., Rogato, A., d'Alcalá, M., and Falciatore, A. (2012). Exploring the molecular basis of responses to light in marine diatoms. J. Exp. Bot. 63, 1575-1591. doi: 10.1093/jxb/ers005

Dominguez, A. A., Lim, W. A., and Qi, L. S. (2016). Beyond editing: repurposing CRISPR-Cas9 for precision genome regulation and interrogation. Nat. Rev. Mol. Cell Biol. 17, 5-15. doi: 10.1038/nrm.2015.2

Dong, Z., and Chen, Y. (2013). Transcriptomics: advances and approaches. Sci. China Life Sci. 56, 960-967. doi: 10.1007/s11427-013-4557-2

Eberhard, S., Finazzi, G., and Wollman, F.-A. (2008). The dynamics of photosynthesis. Annu. Rev. Genet. 42, 463-515. doi: 10.1146/annurev.genet.42.110807.091452

Finazzi, G., Johnson, G. N., Dall'Osto, L., Zito, F., Bonente, G., Bassi, R., et al. (2006). Nonphotochemical quenching of chlorophyll fluorescence in Chlamydomonas reinhardtii. Biochemistry 45, 1490-1498. doi: 10.1021/bi0521588

Gangl, D., Zedler, J. A. Z., Rajakumar, P. D., Martinez, E. M. R., Riseley, A., Włodarczyk, A., et al. (2015). Biotechnological exploitation of microalgae. J. Exp. Bot. 66, 6975-6990. doi: 10.1093/jxb/erv426

Gao, H., Wright, D. A., Li, T., Wang, Y., Horken, K., Weeks, D. P., et al. (2014). TALE activation of endogenous genes in Chlamydomonas reinhardtii. Algal Res. 5, 52-60. doi: 10.1016/j.algal.2014.05.003

Geider, R. J. (1987). Light and temperature dependence of the carbon to chlorophyll a ratio in microalgae and cyanobacteria: implications for physiology and growth of phytoplankton. New Phytol. 106, 1-34. doi: 10.1111/j.14698137.1987.tb04788.x

Genkov, T., Meyer, M., Griffiths, H., and Spreitzer, R. J. (2010). Functional hybrid rubisco enzymes with plant small subunits and algal large subunits: engineered rbcS cDNA for expression in Chlamydomonas. J. Biol. Chem. 285, 19833-19841. doi: 10.1074/jbc.M110.124230 
Gimpel, J. A., Henríquez, V., and Mayfield, S. P. (2015). Metabolic engineering of eukaryotic microalgae: potential and challenges come with great diversity. Front. Microbiol. 6:1376. doi: 10.3389/fmicb.2015.01376

Gong, Y., Hu, H., Gao, Y., Xu, X., and Gao, H. (2011). Microalgae as platforms for production of recombinant proteins and valuable compounds: progress and prospects. J. Industrial Microbiol. Biotechnol. 38, 1879-1890. doi: 10.1007/s10295-011-1032-6

Goss, R., and Jakob, T. (2010). Regulation and function of xanthophyll cycledependent photoprotection in algae. Photosynth. Res. 106, 103-122. doi: 10.1007/s11120-010-9536-x

Hanagata, N., Takeuchi, T., Fukuju, Y., Barnes, D. J., and Karube, I. (1992). Tolerance of microalgae to high $\mathrm{CO}_{2}$ and high temperature. Phytochemistry 31 , 3345-3348. doi: 10.1016/0031-9422(92)83682-O

Hanikenne, M. (2003). Chlamydomonas reinhardtii as a eukaryotic photosynthetic model for studies of heavy metal homeostasis and tolerance. New Phytol. 159, 331-340. doi: 10.1046/j.1469-8137.2003.00788.x

Hlavova, M., Turoczy, Z., and Bisova, K. (2015). Improving microalgae for biotechnology - From genetics to synthetic biology. Biotechnol. Adv. 33, 11941203. doi: 10.1016/j.biotechadv.2015.01.009

Ho, S.-H., Ye, X., Hasunuma, T., Chang, J.-S., and Kondo, A. (2014). Perspectives on engineering strategies for improving biofuel production from microalgae - a critical review. Biotechnol. Adv. 32, 1448-1459. doi: 10.1016/j.biotechadv.2014.09.002

Hsieh, H.-J., Su, C.-H., and Chien, L.-J. (2012). Accumulation of lipid production in Chlorella minutissima by triacylglycerol biosynthesis-related genes cloned from Saccharomyces cerevisiae and Yarrowia lipolytica. J. Microbiol. 50, 526-534. doi: 10.1007/s12275-012-2041-5

$\mathrm{Hu}$, S., Lau, K. W. K., and Wu, M. (2001). Cadmium sequestration in Chlamydomonas reinhardtii. Plant Sci. 161, 987-996. doi: 10.1016/S01689452(01)00501-5

Iwasaki, I., Kurano, N., and Miyachi, S. (1996). Effects of high- $\mathrm{CO}_{2}$ stress on photosystem II in a green alga, Chlorococcum littorale, which has a tolerance to high $\mathrm{CO}_{2}$. J. Photochem. Photobiol. B Biol. 36, 327-332. doi: 10.1016/S10111344(96)07385-X

Jiang, H., and Gao, K. (2004). Effects of lowering temperature during culture on the production of polyunsaturated fatty acids in the marine diatom Phaeodactylum tricornutum (Bacillariophyceae). J. Phycol. 40, 651-654. doi: 10.1111/j.15298817.2004.03112.x

Jiang, W., Brueggeman, A. J., Horken, K. M., Plucinak, T. M., and Weeks, D. P. (2014). Successful transient expression of Cas9 and single guide RNA genes in Chlamydomonas reinhardtii. Eukaryot. Cell 13, 1465-1469. doi: 10.1128/EC.00213-14

Jones, C. S., and Mayfield, S. P. (2012). Algae biofuels: versatility for the future of bioenergy. Curr. Opin. Biotechnol. 23, 346-351. doi: 10.1016/j.copbio.2011.10.013

Karpowicz, S. J., Prochnik, S. E., Grossman, A. R., and Merchant, S. S. (2011). The GreenCut2 resource, a phylogenomically derived inventory of proteins specific to the plant lineage. J. Biol. Chem. 286, 21427-21439. doi: 10.1074/jbc.M111.233734

Kasai, Y., Oshima, K., Ikeda, F., Abe, J., Yoshimitsu, Y., and Harayama, S. (2015). Construction of a self-cloning system in the unicellular green alga Pseudochoricystis ellipsoidea. Biotechnol. Biofuels 8, 1-12. doi: 10.1186/s13068015-0277-0

Kaye, Y., Grundman, O., Leu, S., Zarka, A., Zorin, B., Didi-Cohen, S., et al. (2015). Metabolic engineering toward enhanced LC-PUFA biosynthesis in Nannochloropsis oceanica: overexpression of endogenous $\Delta 12$ desaturase driven by stress-inducible promoter leads to enhanced deposition of polyunsaturated fatty acids in TAG. Algal Res. 11, 387-398. doi: 10.1016/j.algal.2015.05.003

Kim, E.-J., Ma, X., and Cerutti, H. (2015). Gene silencing in microalgae: mechanisms and biological roles. Bioresour. Technol. 184, 23-32. doi: 10.1016/j.biortech.2014.10.119

Kirst, G. O. (1990). Salinity tolerance of eukaryotic marine algae. Annu. Rev. Plant Physiol. Plant Mol. Biol. 41, 21-53. doi: 10.1146/annurev.pp.41.060190.000321

Kobayashi, Y., Harada, N., Nishimura, Y., Saito, T., Nakamura, M., Fujiwara, T., et al. (2014). Algae sense exact temperatures: small heat shock proteins are expressed at the survival threshold temperature in Cyanidioschyzon merolae and Chlamydomonas reinhardtii. Genome Biol. Evol. 6, 2731-2740. doi: 10.1093/gbe/evu216

Lamers, P. P., Janssen, M., De Vos, R. C. H., Bino, R. J., and Wijffels, R. H. (2012). Carotenoid and fatty acid metabolism in nitrogen-starved Dunaliella salina, a unicellular green microalga. J. Biotechnol. 162, 21-27. doi: 10.1016/j.jbiotec.2012.04.018

Lee, D.-J., Chang, J.-S., and Lai, J.-Y. (2015). Microalgae-microbial fuel cell: a mini review. Bioresour. Technol. 198, 891-895. doi: 10.1016/j.biortech.2015.09.061

Lemaire, S., Keryer, E., Stein, M., Schepens, I., Issakidis-Bourguet, E., GérardHirne, C., et al. (1999). Heavy-metal regulation of thioredoxin gene expression in Chlamydomonas reinhardtii. Plant Physiol. 120, 773-778. doi: 10.1104/pp.120.3.773

Lemoine, Y., and Schoefs, B. (2010). Secondary ketocarotenoid astaxanthin biosynthesis in algae: a multifunctional response to stress. Photosynth. Res. 106, 155-177. doi: 10.1007/s11120-010-9583-3

Li, X., Zhang, R., Patena, W., Gang, S. S., Blum, S. R., Ivanova, N., et al. (2016). An indexed, mapped mutant library enables reverse genetics studies of biological processes in Chlamydomonas reinhardtii. Plant Cell 28, 367-387. doi: 10.1105/tpc. 15.00465

Li, Y., Huang, J., Sandmann, G., and Chen, F. (2009). High-light and sodium chloride stress differentially regulate the biosynthesis of astaxanthin in Chlorella zofingiensis (Chlorophyceae). J. Phycol. 45, 635-641. doi: 10.1111/j.15298817.2009.00689.x

Liska, A. J., Shevchenko, A., Pick, U., and Katz, A. (2004). Enhanced photosynthesis and redox energy production contribute to salinity tolerance in Dunaliella as revealed by homology-based proteomics. Plant Physiol. 136, 2806-2817. doi: 10.1104/pp.104.039438

Lopez, D., Casero, D., Cokus, S. J., Merchant, S. S., and Pellegrini, M. (2011). Algal functional annotation tool: a web-based analysis suite to functionally interpret large gene lists using integrated annotation and expression data. BMC Bioinform. 12:282. doi: 10.1186/1471-2105-12-282

Lusser, M., Parisi, C., Plan, D., and Rodríguez-Cerezo, E. (2012). Deployment of new biotechnologies in plant breeding. Nat. Biotechnol. 30, 231-239. doi: $10.1038 /$ nbt. 2142

Markou, G., and Nerantzis, E. (2013). Microalgae for high-value compounds and biofuels production: a review with focus on cultivation under stress conditions. Biotechnol. Adv. 31, 1532-1542. doi: 10.1016/j.biotechadv.2013. 07.011

Maruyama, S., Tokutsu, R., and Minagawa, J. (2014). Transcriptional regulation of the stress-responsive light harvesting complex genes in Chlamydomonas reinhardtii. Plant Cell Physiol. 55, 1304-1310. doi: 10.1093/pcp/pcu068

Mayank, A., Venkatesh, J., and Tran, L. S. P. (2015). Regulation of photosynthesis during abiotic stress-induced photoinhibition. Mol. Plant 8, 1304-1320. doi: 10.1016/j.molp.2015.05.005

Mayfield, S., and Golden, S. (2015). Photosynthetic bio-manufacturing: food, fuel, and medicine for the 21st century. Photosynth. Res. 123, 225-226. doi: $10.1007 / \mathrm{s} 11120-014-0063-\mathrm{z}$

Miyachi, S., Iwasaki, I., and Shiraiwa, Y. (2003). Historical perspective on microalgal and cyanobacterial acclimation to low- and extremely high- $\mathrm{CO}_{2}$ conditions. Photosynth. Res. 77, 139-153. doi: 10.1023/a:1025817616865

Morozova, O., and Marra, M. A. (2008). Applications of next-generation sequencing technologies in functional genomics. Genomics 92, 255-264. doi: 10.1016/j.ygeno.2008.07.001

Müller, P., Li, X.-P., and Niyogi, K. K. (2001). Non-photochemical quenching. A response to excess light energy. Plant Physiol. 125, 1558-1566. doi: 10.1104/pp.125.4.1558

Mussgnug, J. H., Thomas-Hall, S., Rupprecht, J., Foo, A., Klassen, V., McDowall, A., et al. (2007). Engineering photosynthetic light capture: impacts on improved solar energy to biomass conversion. Plant Biotechnol. J. 5, 802-814. doi: 10.1111/j.1467-7652.2007.00285.x

Noor-Mohammadi, S., Pourmir, A., and Johannes, T. W. (2012). Method to assemble and integrate biochemical pathways into the chloroplast genome of Chlamydomonas reinhardtii. Biotechnol. Bioeng. 109, 2896-2903. doi: 10.1002/bit.24569

Perales-Vela, H. V., Peña-Castro, J. M., and Cañizares-Villanueva, R. O. (2006). Heavy metal detoxification in eukaryotic microalgae. Chemosphere 64, 1-10. doi: 10.1016/j.chemosphere.2005.11.024 
Qin, S., Lin, H., and Jiang, P. (2012). Advances in genetic engineering of marine algae. Biotechnol. Adv. 30, 1602-1613. doi: 10.1016/j.biotechadv.2012.05.004

Quaas, T., Berteotti, S., Ballottari, M., Flieger, K., Bassi, R., Wilhelm, C., et al. (2015). Non-photochemical quenching and xanthophyll cycle activities in six green algal species suggest mechanistic differences in the process of excess energy dissipation. J. Plant Physiol. 172, 92-103. doi: 10.1016/j.jplph.2014.07.023

Rajamani, S., Siripornadulsil, S., Falcao, V., Torres, M., Colepicolo, P., and Sayre, R. (2007). "Phycoremediation of heavy metals using transgenic microalgae," in Transgenic Microalgae as Green Cell Factories, eds R. León, A. Galván, and E. Fernández (New York, NY: Springer), 99-109.

Rasala, B. A., Chao, S.-S., Pier, M., Barrera, D. J., and Mayfield, S. P. (2014). Enhanced genetic tools for engineering multigene traits into green algae. PLoS ONE 9:e94028. doi: 10.1371/journal.pone.0094028

Rasala, B. A., Muto, M., Sullivan, J., and Mayfield, S. P. (2011). Improved heterologous protein expression in the chloroplast of Chlamydomonas reinhardtii through promoter and 5 ' untranslated region optimization. Plant Biotechnol. J. 9, 674-683. doi: 10.1111/j.1467-7652.2011.00620.x

Raven, J. A. (2010). Inorganic carbon acquisition by eukaryotic algae: four current questions. Photosynth. Res. 106, 123-134. doi: 10.1007/s11120-010-9563-7

Renaud, S. M., Thinh, L.-V., Lambrinidis, G., and Parry, D. L. (2002). Effect of temperature on growth, chemical composition and fatty acid composition of tropical Australian microalgae grown in batch cultures. Aquaculture 211, 195-214. doi: 10.1016/S0044-8486(01)00875-4

Roháček, K., Bertrand, M., Moreau, B., Jacquette, B., Caplat, C., MorantManceau, A., et al. (2014). Relaxation of the non-photochemical chlorophyll fluorescence quenching in diatoms: kinetics, components and mechanisms. Philos. Trans. R. Soc. Lond. B Biol. Sci. 369:20130241. doi: 10.1098/rstb.2013.0241

Sakai, N., Sakamoto, Y., Kishimoto, N., Chihara, M., and Karube, I. (1995). Chlorella strains from hot springs tolerant to high temperature and high $\mathrm{CO}_{2}$. Energy Convers. Manag. 36, 693-696. doi: 10.1016/0196-8904(95)00100-R

Scibilia, L., Girolomoni, L., Berteotti, S., Alboresi, A., and Ballottari, M. (2015). Photosynthetic response to nitrogen starvation and high light in Haematococcus pluvialis. Algal Res. 12, 170-181. doi: 10.1016/j.algal.2015.08.024

Scranton, M. A., Ostrand, J. T., Fields, F. J., and Mayfield, S. P. (2015). Chlamydomonas as a model for biofuels and bio-products production. Plant J. 82, 523-531. doi: 10.1111/tpj. 12780

Scranton, M. A., Ostrand, J. T., Georgianna, D. R., Lofgren, S. M., Li, D., Ellis, R. C., et al. (2016). Synthetic promoters capable of driving robust nuclear gene expression in the green alga Chlamydomonas reinhardtii. Algal Res. 15, 135-142. doi: 10.1016/j.algal.2016.02.011

Siripornadulsil, S., Traina, S., Verma, D. P. S., and Sayre, R. T. (2002). Molecular mechanisms of Proline-mediated tolerance to toxic heavy metals in transgenic microalgae. Plant Cell 14, 2837-2847. doi: 10.1105/tpc.004853

Sizova, I., Greiner, A., Awasthi, M., Kateriya, S., and Hegemann, P. (2013). Nuclear gene targeting in Chlamydomonas using engineered zinc-finger nucleases. Plant J. 73, 873-882. doi: $10.1111 /$ tpj.12066

Solovchenko, A., and Khozin-Goldberg, I. (2013). High- $\mathrm{CO}_{2}$ tolerance in microalgae: possible mechanisms and implications for biotechnology and bioremediation. Biotechnol. Lett. 35, 1745-1752. doi: 10.1007/s10529-013$1274-7$

Steinbrenner, J., and Sandmann, G. (2006). Transformation of the green alga Haematococcus pluvialis with a phytoene desaturase for accelerated astaxanthin biosynthesis. Appl. Environ. Microbiol. 72, 7477-7484. doi: 10.1128/AEM.01461-06

Stengel, D. B., Connan, S., and Popper, Z. A. (2011). Algal chemodiversity and bioactivity: sources of natural variability and implications for commercial application. Biotechnol. Adv. 29, 483-501. doi: 10.1016/j.biotechadv.2011.05.016

Sun, G., Zhang, X., Sui, Z., and Mao, Y. (2008). Inhibition of pds gene expression via the RNA interference approach in Dunaliella salina (Chlorophyta). Mar. Biotechnol. 10, 219-226. doi: 10.1007/s10126-007-9056-7

Sung, K.-D., Lee, J.-S., Shin, C.-S., Park, S.-C., and Choi, M.-J. (1999). CO2 fixation by Chlorella sp. KR-1 and its cultural characteristics. Bioresour. Technol. 68, 269-273. doi: 10.1016/S0960-8524(98)00152-7
Suresh Kumar, K., Dahms, H.-U., Won, E.-J., Lee, J.-S., and Shin, K.-H. (2015). Microalgae - A promising tool for heavy metal remediation. Ecotoxicol. Environ. Saf. 113, 329-352. doi: 10.1016/j.ecoenv.2014.12.019

Tardif, M., Atteia, A., Specht, M., Cogne, G., Rolland, N., Brugière, S., et al. (2012). PredAlgo: a new subcellular localization prediction tool dedicated to green algae. Mol. Biol. Evol. 29, 3625-3639. doi: 10.1093/molbev/ mss178

Tissot-Lecuelle, G., Purton, S., Dubald, M., and Goldschmidt-Clermont, M. (2014). "Synthesis of recombinant products in the chloroplast," in Plastid Biology, eds S. M. Theg and F.-A. Wollman (New York, NY: Springer), 517-557.

Torricelli, E., Gorbi, G., Pawlik-Skowronska, B., di Toppi, L. S., and Corradi, M. G. (2004). Cadmium tolerance, cysteine and thiol peptide levels in wild type and chromium-tolerant strains of Scenedesmus acutus (Chlorophyceae). Aquat. Toxicol. 68, 315-323. doi: 10.1016/j.aquatox.2004.03.020

Tsai, C.-H., Warakanont, J., Takeuchi, T., Sears, B. B., Moellering, E. R., and Benning, C. (2014). The protein compromised hydrolysis of triacylglycerols 7 (CHT7) acts as a repressor of cellular quiescence in Chlamydomonas. Proc. Natl. Acad. Sci. U.S.A. 111, 15833-15838. doi: 10.1073/pnas.1414567111

Tsuji, N., Hirayanagi, N., Okada, M., Miyasaka, H., Hirata, K., Zenk, M. H., et al. (2002). Enhancement of tolerance to heavy metals and oxidative stress in Dunaliella tertiolecta by $\mathrm{Zn}$-induced phytochelatin synthesis. Biochem. Biophys. Res. Commun. 293, 653-659. doi: 10.1016/S0006-291X(02) 00265-6

USDA Japan Reports (2014). United States Department of Agriculture. Japan takes step Forward to Improve its GE Product Review Process. Available at: usdajapan.org/en/reports/reports2014.html

Waters, E., and Rioflorido, I. (2007). Evolutionary analysis of the small heat shock proteins in five complete algal genomes. J. Mol. Evol. 65, 162-174. doi: 10.1007/s00239-006-0223-7

Whitney, S. M., Houtz, R. L., and Alonso, H. (2011). Advancing our understanding and capacity to engineer nature's $\mathrm{CO}_{2}$-sequestering enzyme. Rubisco. Plant Physiol. 155, 27-35. doi: 10.1104/pp.110.164814

Wobbe, L., Bassi, R., and Kruse, O. (2016). Multi-level light capture control in plants and green algae. Trends Plant Sci. 21, 55-68. doi: 10.1016/j.tplants.2015.10.004

$\mathrm{Wu}, \mathrm{S}$., Xu, L., Huang, R., and Wang, Q. (2011). Improved biohydrogen production with an expression of codon-optimized hemH and lba genes in the chloroplast of Chlamydomonas reinhardtii. Bioresour. Technol. 102, 2610-2616. doi: 10.1016/j.biortech.2010.09.123

Yao, L., Tan, T. W., Ng, Y.-K., Ban, K. H. K., Shen, H., Lin, H., et al. (2015). RNA-Seq transcriptomic analysis with Bag2D software identifies key pathways enhancing lipid yield in a high lipid-producing mutant of the non-model green alga Dunaliella tertiolecta. Biotechnol. Biofuels 8, 1-16. doi: 10.1186/s13068-015$0382-0$

Young, R. E. B., and Purton, S. (2015). Codon reassignment to facilitate genetic engineering and biocontainment in the chloroplast of Chlamydomonas reinhardtii. Plant Biotechnol. J. doi: 10.1111/pbi.12490 [Epub ahead of print].

Zhang, J., Hao, Q., Bai, L., Xu, J., Yin, W., Song, L., et al. (2014). Overexpression of the soybean transcription factor GmDof4 significantly enhances the lipid content of Chlorella ellipsoidea. Biotechnol. Biofuels 7, 1-16. doi: 10.1186/s13068-014-0128-4

Zorin, B., Lu, Y., Sizova, I., and Hegemann, P. (2009). Nuclear gene targeting in Chlamydomonas as exemplified by disruption of the PHOT gene. Gene 432, 91-96. doi: 10.1016/j.gene.2008.11.028

Conflict of Interest Statement: The authors declare that the research was conducted in the absence of any commercial or financial relationships that could be construed as a potential conflict of interest.

Copyright (C) 2016 Guihéneuf, Khan and Tran. This is an open-access article distributed under the terms of the Creative Commons Attribution License (CC BY). The use, distribution or reproduction in other forums is permitted, provided the original author(s) or licensor are credited and that the original publication in this journal is cited, in accordance with accepted academic practice. No use, distribution or reproduction is permitted which does not comply with these terms. 